\title{
PERAN KOMUNITAS DALAM PENCEGAHAN KEHAMILAN TIDAK DIINGINKAN PADA REMAJA
}

\author{
*Nur Fitri Ayu Pertiwi, Atik Triratnawati, Sulistyaningsih
}

Kebidanan, Universitas ‘Aisyiyah Yogyakarta, ${ }^{*}$ email: ayu.fiti08@gmail.com

\section{INFO ARTIKEL}

Riwayat Artikel:

Diterima: 25-02-2020

Disetujui: 22-06-2020

\section{Kata Kunci:}

Kehamilan Remaja

Tidak Diinginkan

Pencegahan

Peran komunitas

ABSTRAK

Abstrak: Kehamilan tidak diinginkan pada remaja merupakan permasalahan global yang perlu diperhatikan. Peran orang tua, teman, dan masyarakat merupakan hal penting dalam upaya pencegahan kehamilan tidak diinginkan pada remaja. Tujuan penelitian untuk mengetahui peran orang tua, teman, dan masyarakat dalam upaya pencegahan kehamilan tidak diinginkan pada remaja. Metode penelitian adalah scoping review menggunakan mesin pencarian pada database PubMed dan Science Direct pada Januari 2009 sampai Desember 2019. Berdasarkan hasil scoping review ditemukan tema : "peran komunitas dalam pencegahan kehamilan tidak diinginkan pada remaja".

Abstract: Unwanted pregnancy in adolescents is a global problem that needs attention. The role of parents, friends, and society is important in efforts to prevent unwanted pregnancy in adolescents. The purpose of this study was to determine the role of parents, friends and the community in efforts to prevent unwanted pregnancy in adolescents. The research method is a scoping review using a search engine in the PubMed and Science Direct database from January 2009 to December 2019. Based on the results of the scoping review, the theme is found: "the role of the community in preventing unwanted pregnancy in adolescents".
\end{abstract}

\section{A. LATAR BELAKANG}

Kehamilan tidak diinginkan pada remaja menyumbang $11 \%$ dari total kelahiran secara global. Remaja yang melahirkan pada usia 10-19 tahun lebih sering ditemui di negara berpenghasilan rendah dan menengah [4], [21]. Pengetahuan kesehatan reproduksi yang rendah terutama tentang batasan hubungan lawan jenis dan kontrasepsi. Selain itu kurangnya kesejahteraan sosial, kemiskinan, dan pemerkosaan bisa menjadi penyebab dari kehamilan tidak diinginkan pada remaja [17].

Kehamilan tidak diinginkan pada remaja sering muncul pada periode awal masa pubertas. Masa awal pubertas merupakan masa awal terjadinya penyimpangan perilaku seks yang berakibat pada kehamilan tidak diinginkan pada remaja. Masyarakat beranggapan bahwa kehamilan tidak diinginkan merupakan kesalahan dari remaja itu sendiri. Remaja yang mengalami kehamilan tidak diinginkan dianggap bertanggungjawab atas perbuatannya dengan cara menikah [7], [18].

Peran komunitas merupakan hal penting yang perlu diperhatikan dalam upaya pencegahan kehamilan tidak diinginkan pada remaja. Peran orang tua, teman, dan lingkungan mempengaruhi remaja berperilaku hingga dapat menyebabkan kehamilan tidak diinginkan [22]. Peran orang tua merupakan salah satu kunci pendidikan seksual dini pada remaja. Remaja perlu diberikan pengawasan dan pendidikan terkait kesehatan reproduksinya sejak masa pubertas hingga masa remaja berakhir. Orang tua dengan tingkat sosial dan ekonomi yang rendah lebih memiliki peluang tidak memberikan pendidikan kesehatan reproduksi untuk anaknya. Hal ini disebabkan waktu yang dimiliki orang tua telah digunakan untuk mencari nafkah sehingga tidak ada waktu untuk memperhatikan anaknya secara detail terutama tentang kesehatan reproduksi anaknya [16].

Pendidikan kesehatan reproduksi yang diberikan kepada remaja tidak hanya mengenai masa pubertas saja, namun perlu terintegrasi dengan pembatasan pergaulan dengan lawan jenis. Selain itu pendidikan mengenai dampak jangka panjang perilaku seks pranikah yaitu kehamilan tidak diinginkan. Remaja perlu mengetahui dampak fisik, psikis, sosial, dan ekonomi yang akan dihadapinya jika terjadi kehamilan tidak diinginkan. Pencegahan kehamilan juga dipengaruhi oleh isu moral, lingkungan, budaya, dan kematangan sosial di lingkungan sekitarnya [8], [14].

Remaja perempuan yang mengalami kehamilan tidak diinginkan akan mencari solusi untuk kehamilannya. Solusi yang sering ditempuh oleh remaja yaitu menikah atau menggugurkan kandungannya. Penguguran kandungan atau aborsi pada negara maju masih diijinkan jika sesuai dengan alasannya. Lingkungan pada negara maju menganggap aborsi merupakan solusi untuk kehamilan tidak diinginkan pada remaja karena berhubungan dengan kesehatan ibu 
dan anak di wilayah tersebut pada masa mendatang. Beberapa negara maju juga telah memiliki program dalam upaya pencegahan kehamilan tidak diinginkan. Program ini bertujuan untuk mengurangi angka kehamilan tidak diinginkan pada remaja dan aborsi pada remaja [1], [7], [20].

Ketidaksiapan remaja dalam menjalani proses kehamilan, persalinan, hingga nifas dapat mempengaruhi kesehatan fisik dan psikis dari remaja itu sendiri. Komplikasi yang mungkin terjadi pada kesehatan ibu diantaranya anemia, pre eklamsi, hipertensi, dan diabetes pada kehamilan. Sedangkan komplikasi yang sering terjadi kepada janin adalah Intrauterine Growth Restriction (IUGR), Berat Bayi Lahir Rendah (BBLR), dan bayi lahir kurang bulan [1], [10], [13], [18].

Dampak kehamilan tidak diinginkan pada remaja tidak hanya pada kondisi fisik dan psikisnya saja, namun status sosial ekonomi remaja tersebut juga belum siap dalam menjalani peran barunya. Remaja perempuan akan berhenti pendidikan formal selama masa kehamilan, sedangkan remaja laki-laki belum memiliki pekerjaan yang layak untuk menghidupi keluarganya. Kurangnya kemampuan sosial ekonomi ini akan berdampak pada kesejahteraan keluarga remaja tersebut [5].

\section{B. METODE PENELITIAN}

\section{Fokus Pertanyaan}

Fokus pertanyaan pada scoping review ini adalah "bagaimana peran komunitas dalam pencegahan kehamilan tidak diinginkan pada remaja?”. Tujuan literature didefinisikan sebagai sintesis penelitian yang bertujuan untuk mengetahui peran orang tua, teman, dan masyarakat mengenai pencegahan kehamilan tidak diinginkan pada remaja. Mengidentifikasi konsepkonsep kunci, kesenjangan dalam penelitian, dan sebagai sumber bukti untuk menginformasikan praktik, kebijakan, dan penelitian tentang peran komunitas dalam pencegahan kehamilan tidak diinginkan pada remaja [9].

\section{Framework Population (P), Exposure (E), Outcome (O) dan Study Design (S)}

Framework Population, Exposure, Outcome dan Study Design (PEOS) digunakan untuk mengembangan fokus pertanyaan dan strategi pencarian. Penggunaan PEOS membantu untuk mengidentifikasi konsep-konsep kunci dalam fokus pertanyaan, mengembangkan istilah pencarian yang sesuai untuk menentukan dan menentukan kriteria inklusi dan ekslusi. PEOS digunakan untuk mengidentifikasi unsur-unsur pertanyaan penelitian kualitatif [11]. Adapun identifikasi unsur-unsur pertanyaan penelitian menggunakan PEOS adalah sebagai berikut :

TABEL 1.

Identifikasi Unsur-Unsur Pertanyaan Penelitian Menggunakan PEOS

\begin{tabular}{lllc}
\hline $\begin{array}{c}\text { Population } \\
\text { and } \\
\text { problems }\end{array}$ & Exposure & $\begin{array}{c}\text { Outcomes or } \\
\text { themes }\end{array}$ & $\begin{array}{c}\text { Study } \\
\text { Design }\end{array}$ \\
\hline Adolescent & Prevention & Community & Qualitative \\
Teenager & Unwanted & Role Study \\
Teen & Pregmancy & Role of Parent \\
& & Role of & \\
& & Friends of & \\
& & Role & \\
& & Community & \\
& &
\end{tabular}

\section{Identifikasi Studi yang Relevan}

Peneliti melakukan scoping review dengan identifikasi studi literature. Langkah pertama yaitu pembuatan framework sebagai acuan untuk menentukan kriteria inklusi dan eksklusi agar terdapat fokus dalam pencarian data. Kedua, menyusun keyword yang difokuskan pada framework. Ketiga, keyword yang sudah ditetapkan dimasukkan ke dalam mesin pencarian database PubMed dan Science Direct. Keempat, setelah ditemukan artikel pada database tersebut kemudian disimpan dalam mesin bibliography Zotero. Data yang sudah terinput di Zotero dipilih sesuai dengan framework. Artikel yang tidak sesuai dengan framework dikeluarkan dari folder "relevan". Proses pemilihan artikel akan dibahas di Prisma Flowchart. Keyword yang digunakan dalam pencarian database PubMed dam Science Direct adalah "community role" AND "unwanted pregnancy" OR "adolescent pregnancy" OR "teen pregnancy" OR "teenager pregnancy" AND "prevention".

\section{Prisma Flowchart}

Prisma Flowchart adalah diagram pelaporan untuk tinjauan sistematis pada proses literature review untuk menjelaskan alur pencarian artikel. Adapun Prisma Flowchart dalam penelitian ini : 


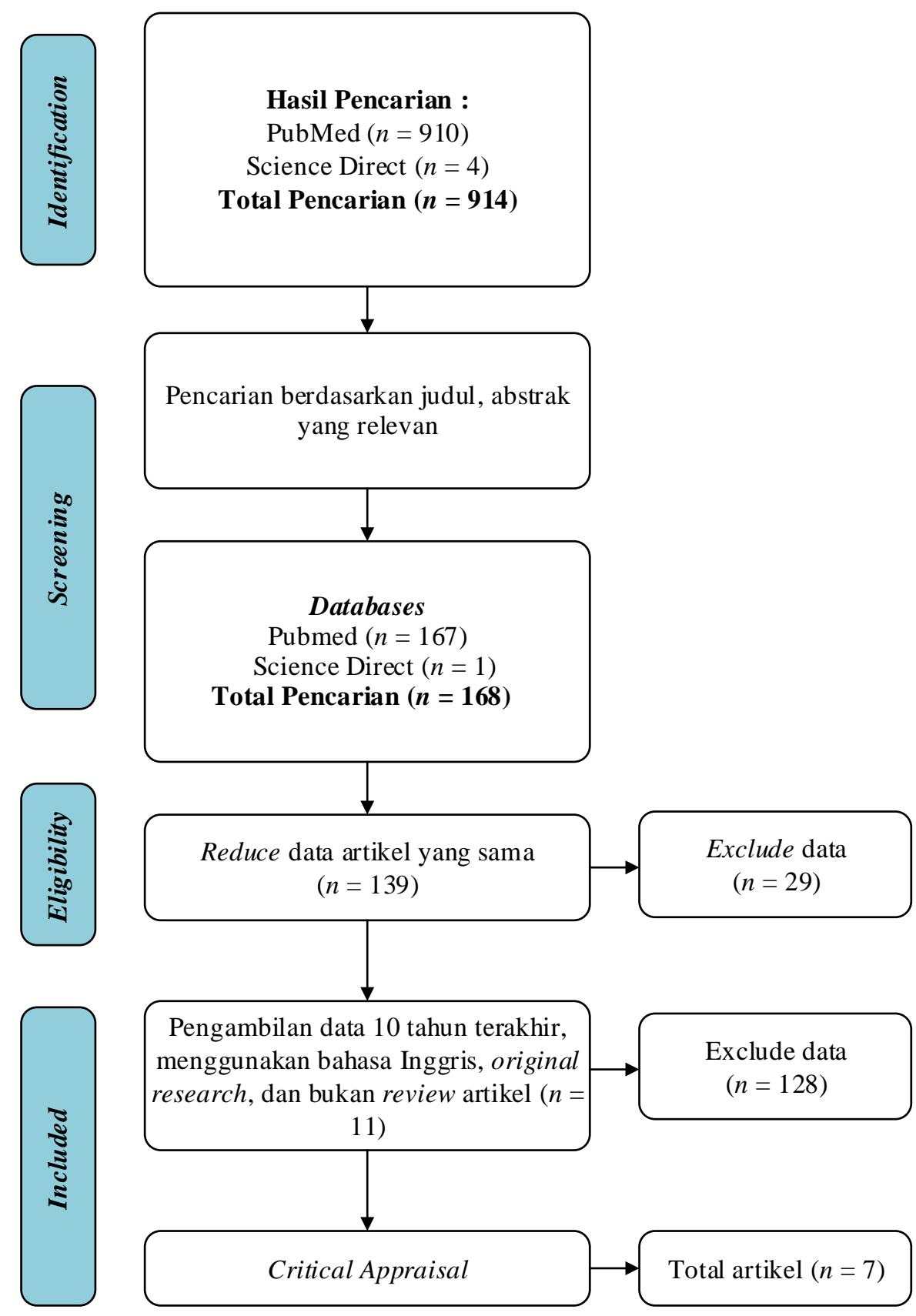

Gambar 1. Prisma Flowchart Peran Komunitas dalam Pencegahan Kehamilan Tidak Diinginkan pada Remaja

\section{Ekstraksi Data}

TABEL 2.

Ekstraksi Data Peran Komunitas dalam Pencegahan Kehamilan Tidak Diinginkan pada Remaja

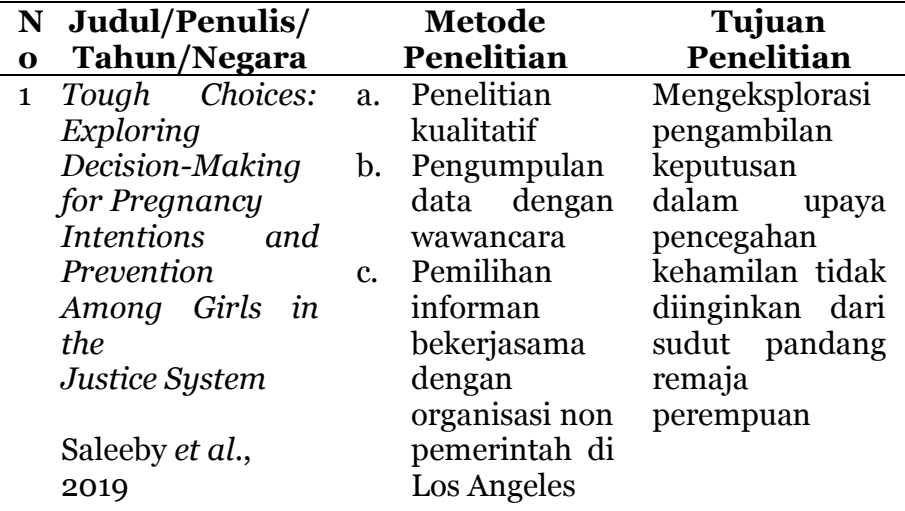
Tema Hasil Penelitian 


\begin{tabular}{|c|c|c|c|c|c|}
\hline & Amerika Serikat & $\begin{array}{l}\text { d. Analisis data } \\
\text { menggunakan } \\
\text { analisis } \\
\text { tematik }\end{array}$ & & $\begin{array}{l}\text { c. Remaja mengungkapkan } \\
\text { merasa berhak atas } \\
\text { keputusan yang dia } \\
\text { ambil tentang tubuhnya } \\
\text { d. Remaja } \\
\text { menggambarkan bahwa } \\
\text { lingkungan menganggap } \\
\text { bahwa topik kontrasepsi } \\
\text { merupakan hal yang } \\
\text { tabu } \\
\text { e. Terdapat temuan } \\
\text { mengenai kurangnya } \\
\text { akses informasi } \\
\text { kesehatan reproduksi } \\
\text { pada remaja terutama } \\
\text { mengenai kontrasepsi }\end{array}$ & $\begin{array}{ll}\text { d. } & \text { Pendidikan kesehatan } \\
\text { reproduksi dapat diberikan } \\
\text { di sekolah formal }\end{array}$ \\
\hline 2 & $\begin{array}{l}\text { A qualitative } \\
\text { study of factors } \\
\text { influencing } \\
\text { contraceptive } \\
\text { choice among } \\
\text { adolescent } \\
\text { school-based } \\
\text { health center } \\
\text { patients al., } \\
\text { Hoopes et al } \\
2015 \\
\text { Amerika Serikat }\end{array}$ & $\begin{array}{ll}\text { a. } & \text { Penelitian } \\
\text { kualitatif } \\
\text { b. }\end{array}$ & $\begin{array}{l}\text { Mengeksplorasi } \\
\text { sikap dan } \\
\text { pengalaman } \\
\text { remaja } \\
\text { perempuan } \\
\text { dengan } \\
\text { kontrasepsi }\end{array}$ & 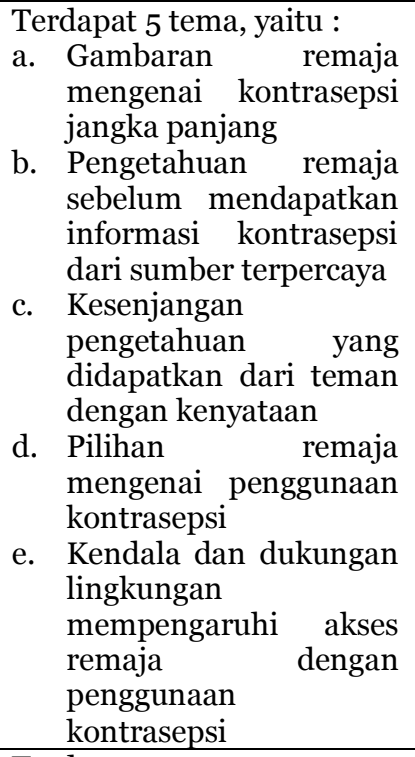 & $\begin{array}{l}\text { Penyedia layanan kesehatan } \\
\text { pada tingkat primer diharapkan } \\
\text { dapat memberikan pendidikan } \\
\text { mengenai kesehatan reproduksi } \\
\text { yang komperhensif. Pendidikan } \\
\text { kesehatan yang tidak hanya } \\
\text { terfokus pada masa pubertas } \\
\text { saja, namun mengenai } \\
\text { kontrasepsi juga. }\end{array}$ \\
\hline 3 & $\begin{array}{l}\text { Applying the } \\
\text { Theory of } \\
\text { Reasoned Action } \\
\text { to Understanding } \\
\text { Teen } \\
\text { Pregnancy with } \\
\text { American Indian } \\
\text { Communities } \\
\text { Dippel et al., } 2017 \\
\text { Amerika Serikat }\end{array}$ & $\begin{array}{ll}\text { a. } & \text { Penelitian } \\
\text { kualitatif } \\
\text { b. }\end{array}$ & $\begin{array}{l}\text { Mengidentifikas } \\
\text { i penyebab } \\
\text { tingkat } \\
\text { kehamilan tidak } \\
\text { diinginkan pada } \\
\text { remaja yang } \\
\text { tinggi pada } \\
\text { gadis Indian } \\
\text { Amerika }\end{array}$ & $\begin{array}{l}\text { Terdapat } 3 \text { tema yang } \\
\text { diidentifikasi, yaitu : } \\
\text { a. Remaja menerima } \\
\text { kehamilannya dan } \\
\text { bayinya karena bayi } \\
\text { yang dilahirkan tidak } \\
\text { bersalah } \\
\text { b. Rata-rata remaja tidak } \\
\text { dapat melanjutkan } \\
\text { pendidikan karena } \\
\text { kehamilannya } \\
\text { c. Kurangnya informasi } \\
\text { mengenai kesehatan } \\
\text { reproduksi dan batasan } \\
\text { hubungan lawan jenis }\end{array}$ & $\begin{array}{l}\text { Program pencegahan } \\
\text { kehamilan yang komperhensif } \\
\text { dapat diterapkan sesuai dengan } \\
\text { kebutuhan remaja. Pentingnya } \\
\text { pengetahuan yang lengkap, } \\
\text { lingkungan yang baik, dan } \\
\text { dukungan sosial yang memadai } \\
\text { akan menurunkan angka } \\
\text { kehamilan tidak diinginkan } \\
\text { pada remaja. Remaja } \\
\text { menginginkan mendapatkan } \\
\text { informasi kesehatan dari } \\
\text { pendidikan formal. }\end{array}$ \\
\hline 4 & 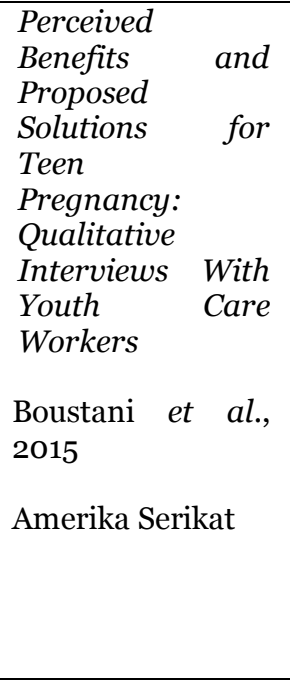 & $\begin{array}{ll}\text { a. } & \text { Penelitian } \\
\text { kualitatif } \\
\text { b. Pengumpulan } \\
\text { data dengan } \\
\text { wawancara } \\
\text { semi } \\
\text { terstruktur } \\
\text { c. Analisis data } \\
\text { menggunakan } \\
\text { analisis } \\
\text { tematik }\end{array}$ & $\begin{array}{l}\text { Mengeksplorasi } \\
\text { persepsi } \\
\text { perawat khusus } \\
\text { remaja } \\
\text { mengenai } \\
\text { kebutuhan } \\
\text { remaja terutama } \\
\text { berkaitan } \\
\text { dengan } \\
\text { kebutuhan } \\
\text { kesehatan } \\
\text { reproduksi }\end{array}$ & $\begin{array}{l}\text { Terdapat } 4 \text { kategori utama } \\
\text { yang diidentifikasi, yaitu: } \\
\text { a. Resiko kehamilan pada } \\
\text { remaja sangat tinggi } \\
\text { secara fisik maupun } \\
\text { psikis dari remaja } \\
\text { tersebut } \\
\text { b. Remaja rengan } \\
\text { kehamilan } \\
\text { diinginkan tidak } \\
\text { berusaha mengasuh } \\
\text { anak mereka dengan } \\
\text { baik } \\
\text { c. Remaja menyadari } \\
\text { bahwa kehamilan diusia } \\
\text { dini anan } \\
\text { mempengaruhi } \\
\text { perekonomian mereka } \\
\text { di masa mendatang } \\
\end{array}$ & $\begin{array}{lrr}\text { Pendidikan } & \text { kesehatan } \\
\text { reproduksi } & \text { sangat } & \text { dibutuhkan } \\
\text { remaja } & \text { dalam } & \text { upaya } \\
\text { pencegahan } & \text { kehamilan tidak } \\
\text { diinginkan. } & \text { Informasi } \\
\text { mengenai batasan } & \text { hubungan } \\
\text { dengan lawan } & \text { jenis, } \\
\text { kontrasepsi, dan dampak } \\
\text { kehamilan tidak diinginkan } \\
\text { perlu diberikan kepada remaja. }\end{array}$ \\
\hline
\end{tabular}




\begin{tabular}{|c|c|c|c|c|c|}
\hline & & & & $\begin{array}{lr}\text { d. Solusi untuk } & \text { remaja } \\
\text { yang } & \text { mengalami } \\
\text { kehamilan } & \text { tidak } \\
\text { diinginkan } & \text { yaitu } \\
\text { mendidik } & \text { remaja } \\
\text { dengan kenyataan akan } \\
\text { memiliki bayi dan cara } \\
\text { perawatannya }\end{array}$ & \\
\hline 5 & $\begin{array}{l}\text { Teen Pregnancy } \\
\text { Experiences of } \\
\text { Sexual Minority } \\
\text { Women } \\
\text { Charlton et al, } \\
2012 \\
\text { Amerika Serikat }\end{array}$ & $\begin{array}{ll}\text { a. } & \text { Penelitian } \\
\text { kualitatif } \\
\text { b. } & \text { Data } \\
\text { dikumpulkan } \\
\text { dengan } \\
\text { wawancara } \\
\text { semi } \\
\text { terstruktur } \\
\text { c. Analisis data } \\
\text { menggunakan } \\
\text { metode } \\
\text { konseptual }\end{array}$ & $\begin{array}{l}\text { Menggambarka } \\
\mathrm{n} \text { pengalaman } \\
\text { kehamilan } \\
\text { remaja dan } \\
\text { resiko yang } \\
\text { mungkin } \\
\text { dialaminya }\end{array}$ & $\begin{array}{l}\text { Terdapat 5 tema yang } \\
\text { diidentifikasi, yaitu : } \\
\text { a. Seksualitas } \\
\text { b. Riwayat hidup dan } \\
\text { faktor } \\
\text { kehamilan sebelum } \\
\text { c. Penyalahgunaan } \\
\text { kontrasepsi } \\
\text { pemaksaan dan } \\
\text { d. Reaksi terhadap } \\
\text { kehamilan kehamilan } \\
\text { e. Dampak pada } \\
\\
\begin{array}{l}\text { yang terjadi remaja } \\
\text { rang }\end{array}\end{array}$ & $\begin{array}{ll}\text { a. } & \text { Kehamilan tidak diinginkan } \\
\text { terjadi pada usia 12-19 } \\
\text { tahun. }\end{array}$ \\
\hline 6 & $\begin{array}{l}\text { Parent-Teen } \\
\text { Communication } \\
\text { about Sexual and } \\
\text { Reproductive } \\
\text { Health: Cohort } \\
\text { Differences by } \\
\text { Race/Ethnicity } \\
\text { and Nativity } \\
\text { Lantos et al., } 2019 \\
\text { Amerika Serikat }\end{array}$ & 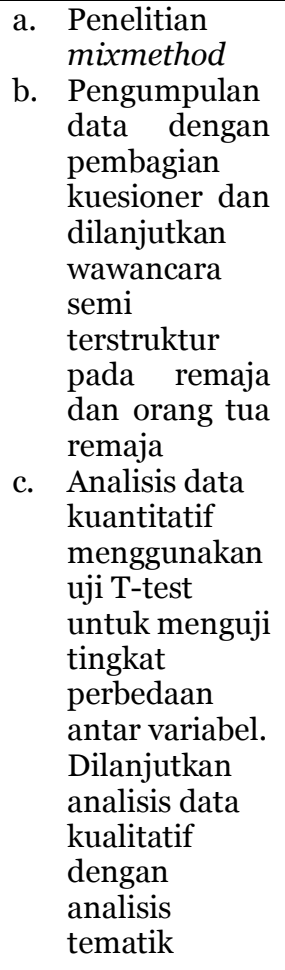 & $\begin{array}{l}\text { Mengeksplorasi } \\
\text { pandangan } \\
\text { orang tua dan } \\
\text { remaja } \\
\text { mengenai } \\
\text { diskusi } \\
\text { mengenai } \\
\text { kesehatan } \\
\text { reproduksi } \\
\text { terutama } \\
\text { mengenai } \\
\text { penundaan seks } \\
\text { dan penggunaan } \\
\text { kontrasepsi }\end{array}$ & $\begin{array}{l}\text { Terdapat } 2 \text { tema yang } \\
\text { diidentifikasi, yaitu : } \\
\text { a. Prevalensi orang tua } \\
\text { yang memiliki anak } \\
\text { laki-laki lebih tinggi } \\
\text { dalam membahas } \\
\text { kesehatan reproduksi } \\
\text { dibandingkan orang tua } \\
\text { yang memiliki anak } \\
\text { perempuan } \\
\text { b. Program pencegahan } \\
\text { kehamilan tidak } \\
\text { diinginkan sangat } \\
\text { dibutuhkan remaja } \\
\text { terutama peningkatan } \\
\text { komunikasi antar orang } \\
\text { tua dan remaja }\end{array}$ & $\begin{array}{ll}\text { a. } & \text { Temuan baru tentang } \\
\text { prevalensi diskusi orang tua } \\
\text { dan remaja mengenai } \\
\text { kesehatan reproduksi. } \\
\text { b. Peningkatan komunikasi } \\
\text { antar orang tua dan remaja } \\
\text { mengenai kesehatan } \\
\text { reproduksi sangat penting. }\end{array}$ \\
\hline 7 & $\begin{array}{l}\text { Male adolescents' } \\
\text { role in pregnancy } \\
\text { prevention and } \\
\text { unintended in } \\
\text { pregnancy Victoria: } \\
\text { rural care } \\
\text { health } \\
\text { Professional's and } \\
\text { educators } \\
\text { perspectives } \\
\text { Connor et al., } \\
2018\end{array}$ & $\begin{array}{ll}\text { a. } & \text { Penelitian } \\
\text { kualitatif } \\
\text { b. }\end{array}$ & $\begin{array}{l}\text { Mengeksplorasi } \\
\text { kehamilan tidak } \\
\text { diinginkan pada } \\
\text { remaja } \\
\text { berdasarkan } \\
\text { sudut pandang } \\
\text { remaja laki-laki }\end{array}$ & $\begin{array}{l}\text { Terdapat 5 tema yang } \\
\text { diidentifikasi, yaitu : } \\
\text { a. Perbedaan pandangan } \\
\text { menurut gender bahwa } \\
\text { laki-laki dianggap wajar } \\
\text { melakukan hubungan } \\
\text { seks pranikah } \\
\text { b. Laki-laki sulit terlibat } \\
\text { dalam usaha } \\
\text { pencegahan kehamilan } \\
\text { tidak diinginkan pada } \\
\text { remaja } \\
\text { c. Resiko terpapar alkohol } \\
\text { dan penyalahgunaan } \\
\text { zat terlarang lebih } \\
\text { tinggi pada gender laki- } \\
\text { laki } \\
\text { d. Pedesaan dengan status } \\
\text { sosial ekonomi rendah } \\
\text { serta akses pelayanan } \\
\text { kesehatan yang sulit } \\
\text { akan meningkatkan } \\
\text { kemungkinan }\end{array}$ & \begin{tabular}{ll} 
a. & \multicolumn{2}{l}{ Sebagai upaya pencegahan } \\
kehamilan tidak diinginkan, \\
remaja laki-laki perlu \\
menjadi fokus dalam \\
pencegahannya \\
b. Remaja laki-laki perlu \\
mendapatkan akses \\
pelayanan kesehatan \\
reproduksi yang baik \\
c. Remaja laki-laki memiliki \\
rasa tanggungjawab terkait \\
dengan kehamilan tidak \\
diinginkan yang terjadi
\end{tabular} \\
\hline
\end{tabular}


terjadinya kehamilan tidak diinginkan pada remaja

e. Setelah terjadi

kehamilan tidak

diinginkan, remaja laki-

laki akan fokus pada

peran barunya sebagai

calon bapak

\section{Mapping / Scoping Literatur}

Berdasarkan jurnal yang didapat sejumlah 7 jurnal. Seluruh jurnal berasal dari negara maju yaitu Amerika Serikat dan Australia. Hasil scoping review ditemukan beberapa tema yang relevan dengan fokus review sebagai berikut :

TABEL 3.

Mapping Literature

\begin{tabular}{|c|c|c|}
\hline No & Tema & Sub Tema \\
\hline 1 & $\begin{array}{l}\text { Pendidikan } \\
\text { Kesehatan } \\
\text { Reproduksi }\end{array}$ & $\begin{array}{llr}\text { a. } & \text { Pendidikan } \\
& \text { reproduksi tesian } \\
& \text { kontrasepsi } i^{1,2,4,5,6} \\
\text { b. } & \text { Pendidikan kesehatan } \\
& \text { reproduksi tentang } \\
& \text { hubungan dengan lawan } \\
& \text { jenis } 3,4\end{array}$ \\
\hline 2 & $\begin{array}{l}\text { Upaya } \\
\text { Pencegahan } \\
\text { Kehamilan }\end{array}$ & $\begin{array}{l}\text { a. Pencegahan kehamilan } \\
\text { dari remaja }{ }^{1,34,6,7} \\
\text { b. Pencegahan kehamilan } \\
\text { dari orang tua }{ }^{1,6} \\
\text { c. Pencegahan kehamilan } \\
\text { dari lingkungan } 1,2,3 \\
\end{array}$ \\
\hline 3 & $\begin{array}{l}\text { Harapan } \\
\text { Remaja }\end{array}$ & $\begin{array}{ll}\text { a. Harapan remaja } \\
\text { mendapatkan } \\
\text { pendidikan kesehatan } \\
\text { reproduksi } \\
\text { b. Harapan remaja remaja } \\
\text { tentang masa depannya, }\end{array}$ \\
\hline
\end{tabular}

\section{HASIL DAN PEMBAHASAN}

1. Hasil Scoping Review

\section{a. Pendidikan Kesehatan Reproduksi}

Kehamilan tidak diinginkan pada remaja salah satu penyebabnya yaitu kurangnya pengetahuan kesehatan reproduksi. Akses pelayanan kesehatan reproduksi untuk remaja masih dirasa sangat kurang. Pemahaman bahwa kesehatan reproduksi adalah hal yang tabu menjadi bahasan dengan remaja [19]. Seorang remaja mengungkapkan bahwa orang tuanya menyuruhnya menjaga diri dengan mengatakan

"tutup kakimu. Jangan biarkan laki-laki melihat dirimu yang terlalu menarik perhatian mereka. Jangan mudah percaya dengan lakilaki." (Remaja)

Pendidikan kesehatan reproduksi yang diharapkan remaja adalah pendidikan kesehatan reproduksi yang menyeluruh tidak hanya mengenai masa pubertas saja. Bahasan mengenai kontrasepsi dan dampak kehamilan tidak diinginkan merasa diperlukan oleh remaja. salah satu jurnal [12] menjelaskan bahwa remaja berpendapat

"kata kontrasepsi sangat halus, tetapi dibalik kata seperti itu tersimpan makna bahwa kamu sedang aktif berhubungan seksual." (Remaja)

Remaja merasa infomasi yang dimiliki terbatas, salah satunya batasan hubungan lawan jenis. Setelah terjadi kehamilan tidak diinginkan, remaja disalahkan oleh orang-orang sekitar mengenai kejadian yang dialaminya. Menurut salah satu jurnal [6], pandangan mengenai remaja yang mengalami kehamilan tidak diinginkan yaitu

"orang-orang lebih memandang rendah remaja perempuan yang mengalami kehamilan tidak diinginkan. Mereka diibaratkan seorang pelacur."(Remaja)

\section{b. Upaya Pencegahan Kehamilan}

Sebagian remaja mengerti akan pentingnya menjaga hubungan mereka agar tidak terjadi kehamilan. Namun, remaja tidak memiliki pengetahuan yang cukup untuk mencegah terjadinya kehamilan [4]. Remaja laki-laki berusaha mencegah terjadinya kehamilan pada pasangannya seperti pernyataan dalam salah satu jurnal yaitu

"berbicara mengenai penggunaan kondom dalam upaya pencegahan kehamilan sudah dilakukan.Namun tidak dapat mencegah kehamilan"

Pencegahan kehamilan tidak diinginkan juga dilakukan oleh orang tua. Pendidikan kesehatan reproduksi dapat diberikan kepada remaja sejak masa pubertas. Pendidikan kesehatan reproduksi selama ini belum menyeluruh. Bahasan mengenai kontrasepsi dan batasan hubungan dengan lawan jenis belum dibahas. Hal ini dianggap tabu oleh sebagian orang. Remaja lakilaki memiliki prevalensi lebih tinggi mengenai diskusi mengenai kesehatan reproduksinya dengan orang tua dibandingkan dengan remaja perempuan [4].

Pencegahan kehamilan tidak diinginkan bukan hanya dari sisi remaja dan orang tuanya saja, namun berkaitan dengan kondisi lingkungan tempat tinggal remaja tersebut. Remaja mengungkapkan bahwa tidak 
mendapatkan dukungan yang baik di lingkungannya seperti yang diungkapkan dalam kalimat [19].

"saya hanya mendapatkan sedikit cinta dari lingkungan saya. Saya hanya ingin mencari kasih sayang dan tidak memahami bahwa akan menjadi seperti ini"

\section{c. Harapan Remaja}

Remaja yang mengalami kehamilan tidak diinginkan memiliki harapan pendidikan mengenai kesehatan reproduksi terutama mengenai kontrasepsi agar tidak terjadi kehamilan tidak diinginkan pada kehamilan berikutnya. Remaja mengungkapkan dalam kalimat berikut [12].

"saya tidak tahu mengenai alat kontrasepsi. Saya hanya paham bahwa jika saya hamil maka saya tidak akan mendapatkan menstruasi"

Keinginan untuk merangkai masa depan juga diiungkapkan remaja. remaja laki-laki ingin berusaha untuk menjalankan peran terbaiknya sebagai seorang bapak. Seperti kalimat berikut ini [4].

"remaja laki-laki memiliki niat baik untuk bertanggungjawab atas perbuatannya. Mereka memahami masa depan tanpa pekerjaan dan akan menyelesaikan masalah tersebut."

\section{Pembahasan}

\section{a. Pendidikan Kesehatan Reproduksi}

Pendidikan kesehatan reproduksi dan remaja merupakan hal yang tidak dapat dipisahkan. Remaja membutuhkan pendidikan kesehatan reproduksi untuk melewati masa pubertas hingga dewasa. Salah satu bahasan yang remaja butuhkan yaitu mengenai batasan hubungan dengan lawan jenis. Selain itu pendidikan mengenai kontrasepsi juga perlu dilakukan. Bukan berarti memberikan kesempatan remaja untuk melakukan hubungan seksual pranikah, namun juga diberikan pendidikan mengenai dampak hubungan seks pranikah. Sehingga diharapkan remaja dapat mengetahui segala resiko terharap perbuatannya. Remaja dengan kehamilan tidak diinginkan mengungkapkan bahwa tidak memahami dampak perbuatannya. Sebagian remaja telah memahami bahwa kehamilan terjadi jika menstruasi berhenti. Remaja tidak memikirkan dampak jangka panjang kehamilan tidak diinginkan yang akan berpengaruh pada fisik, psikis, sosial, dan ekonominya [2], [12], [19].

Beberapa remaja mengungkapkan bahwa pendidikan kesehatan reproduksi dapat diberikan bersama dengan pendidikan formal. Hal ini bukan tanpa alasan, remaja merasa selama ini kurang mendapatkan pendidikan tersebut. Situasi lingkungan remaja juga tidak memberikan informasi pendidikan yang tepat mengenai kesehatan reproduksi. Rasa ingin tahu yang dimiliki remaja mengenai seksualitas dan tidak mendapatkan pendidikan yang tepat dapat membuat remaja melakukan hal yang sebetulnya bisa dihindari yaitu seks pranikah [3], [15].

Lingkungan sosial remaja juga mempengaruhi potensial terjadinya kehamilan tidak diinginkan. Pendidikan seksualitas, hubungan antar lawan jenis, dan kontrasepsi masih di anggap sebagai hal yang tabu. Namun begitu remaja mengalami kehamilan tidak diinginkan, remaja akan disalahkan atas perbuatannya tanpa mengevaluasi keadaan lingkungan selama ini. Remaja perempuan cenderung lebih disalahkan karena tidak dapat menjaga dirinya sehingga terjadi kehamilan tidak diinginkan [2], [6].

\section{b. Upaya Pencegahan Kehamilan}

Pencegahan kehamilan pada remaja telah dilakukan, namun karena pendidikan yang tidak memadai remaja masih bingung dalam usaha pencegahannya. Beberapa artikel menjelaskan bahwa remaja laki-laki telah menggunakan kondom dan tetap terjadi kehamilan [4], [6], [15], [19].

Pendidikan kesehatan reproduksi perlu diberikan kepada remaja. Remaja merasa dirinya tidak diperhatikan sehingga tumbuh diatas ketidak pahaman mengenai kesehatan reproduksi. Mencari tahu informasi dari sumber yang tidak dapat dipercaya dapat membuat remaja semakin penasaran hingga berujung mencoba-coba seks pranikah. Beberapa remaja mengungkapkan bahwa dirinya merasa tidak dicintai oleh lingkungannya sehingga mencari cinta dengan pasangannya [15], [19].

Diskusi mengenai kesehatan reproduksi antara orang tua dan remaja juga perlu ditingkatkan. Orang tua beranggapan bahwa bahasan mengenai kesehatan reproduksi adalah hal yang tabu dan remaja tidak perlu tahu. Namun hal itu justru membuat remaja penasaran dan mencoba-coba hal tersebut. Beberapa jurnal menjelaskan bahwa komunikasi orang tua dan remaja mengenai kesehatan reproduksi lebih tinggi kepada remaja laki-laki dibandingkan dengan remaja perempuan [6], [12], [19].

\section{c. Harapan Remaja}

Dampak kehamilan tidak diinginkan salah satunya yaitu putus sekolah. Remaja berharap bahwa dia masih bisa melanjutkan sekolahnya sehingga bisa mendapatkan pekerjaan di masa depannya. Remaja menyesal tidak memahami dampak perilaku seks pranikah yang dia lakukan. Harapan kedepannya, pendidikan mengenai kesehatan reproduksi, dampak perilaku seks 
pranikah, dan kontrasepsi diberikan sehingga dapat mengurani kemungkinan kasus yang sama terjadi pada remaja yang lain [2], [6], [12], [19].

Remaja laki-laki dengan pasangan yang mengalami kehamilan tidak diinginkan merasa bertanggungjawab atas bayi yang dikandung oleh pasangannya. Mereka memahami bahwa belum memiliki kehidupan ekonomi yang mapan, namun akan berusaha semaksimal mungkin dalam menatap masa depannya [4], [19].

\section{SIMPULAN DAN SARAN}

Berdasarkan hasil review jurnal menggunakan scoping review ditemukan tema :

1. Pendidikan Kesehatan Reproduksi

2. Upaya Pencegahan Kehamilan

3. Harapan Remaja

Berdasarkan review jurnal yang ditemukn, tidak ditemukan hasil paper dari Negara Berkembang, sehingga review peran komunitas dalam pencegahan kehamilan tidak diinginkan pada remaja merupakan gap masalah yang perlu diteliti di Negara Berkembang, khususnya Indonesia.

\section{UCAPAN TERIMAKASIH}

Penulis mengucapkan terimakasih kepada pembimbing, sehingga penulis dapat menyelesaikan penyusunan scoping review ini.

\section{DAFTAR RUJUKAN}

[1] Aziato, L., Hindin, M., Maya, E., Manu, A., Amuasi, S., Lawerh, R., Ankomah, A. 2016. Adolescents' responses to an unintended pregnancy in Ghana: A qualitative study. Elsevier Ltd. doi: 10.1016/j.jpag.2016.06.005.

[2] Boustani, M., Frazier, S., Hartley, C., Meinzer, M., Hedemann, E. 2015. Perceived Benefits and Proposed Solutions for Teen Pregnancy: Qualitative Interviews With Youth Care Workers. American Journal of Orthopsychiatry. http://dx.doi.org/10.1037/ortooooo40

[3] Charlton, B., Nava-Coulter, B., Coles, M., Katz-Wise, S. 2012. Teen Pregnancy Experiences of Sexual Minority Women. Elsevier

Inc. https://doi.org/10.1016/j.jpag.2019.05.009

[4] Connor, S., Edvardsson, K., Spelten, E. 2018. Male adolescents' role in pregnancy prevention and unintended pregnancy in rural Victoria: health care Professional' $\mathrm{s}$ and educators 'perspectives. BMC Pregnancy and Childbirth. doi : 10.1186/s12884-0181886-y

[5] Conroy, K., Engelhart, T., Martins, Y., Huntington, N., Snyder, A., Coletti, K., Cox, J. 2016. The Enigma of Rapid Repeat Pregnancy: A Qualitative Study of Teen Mothers. Elsevier

Inc. http://dx.doi.org/10.1016/j.jpag.2015.12.003

[6] Dippel,E., Hanson, J., McMahon, T., Griese, E., Kenyon, D. 2017. Applying the Theory of Reasoned Action to Understanding Teen Pregnancy with American Indian Communities. Maternal and Child Health Journal. doi : 10.1007/s10995-017-2262-7

[7] Ekstrand, M., Tyden, T., Darj, E., Larsson, M. 2009. An Illusion of Power: Qualitative Perspectives On Abortion Decision-Making Among Teenage Women In Sweden . Perspectives on Sexual and Reproductive Health. doi: 10.1363/4117309
[8] Fisher, M., Shlomo, B., Solt, I., Burke, Y. 2015. Pregnancy Prevention and Termination of Pregnancy in Adolescence: Facts, Ethics, Law and Politics. Israel Medical Association. PMID: 26757560

[9] Fuller, T., White, C., Chu, J., Dean, D., Clemmons, N., Chaparro, C., Thames, J., Henderson, A., King, P. 2018 Social Determinants and Teen Pregnancy Prevention: Exploring the Role of Nontraditional Partnerships. Health Promotion Practice. doi:10.1177/1524839916680797

[10] Habitu, Y., Yalew, A., Bisetegn, T. 2018. Prevalence and Factors Associated with Teenage Pregnancy, Northeast Ethiopia , 2017 : A Cross-Sectional Study. Journal of Pregnancy. doi:10.1155/2018/1714527

[11] Halas, G., Schultz, A.S.H., Rothney, J., Goertzen, L., Wener, P., Katz, A. 2015. A scoping review protocol to map the research foci trends in tobacco control over the last decade. BMJ Open. https://doi.org/10.1136/bmjopen-2014-006643.

[12] Hoopes, A., Gilmore, K., Cady, J., Akers, A., Ahrens, K. 2015. A qualitative study of factors influencing contraceptive choice among adolescent school-based health center patients. Journal of Pediatric and Adolescent Gynecology. doi 10.1016/j.jpag.2015.09.011

[13] Hossain, G., Mahumud, R., Saw, A. 2016. Prevalence Of Child Marriage Among Bangladeshi Women And Trend Of Change Over Time. Journal Of Biosocial Science. doi:10.1017/Soo21932015000279

[14] Lamina, M. 2015. Prevalence and Determinants of Unintended Pregnancy among Women in SouthWestern Nigeria. Ghana Medical Journal. doi : http://dx.doi.org/10.4314/gmj.v49i3.10

[15] Lantos, H., Manlove., Wildsmith, E., Faccio, B., Guzman, L., Moore, K. 2019. Parent-Teen Communication about Sexual and Reproductive Health: Cohort Differences by Race/Ethnicity and Nativity. International Journal of Environmental Research and Public Health. doi:10.3390/ijerph16050833

[16] Mann, E., Cardona, V., Gomes, C. 2015. Beyond the discourse of reproductive choice: narratives of pregnancy resolution among Latina/o teenage parents. Culture, Health \& Sexuality. doi:10.1080/13691058.2015.1038853

[17] Mccleary-sills, J., Douglas Z., Rwehumbiza, A., Hamisi, A., Mabala, R. 2010. Gendered norms , sexual exploitation and adolescent pregnancy in rural Tanzania, RHM. Reproductive Health Matters. doi:10.1016/So968- 8080(13)41682-8.

[18] Okigbo, C., Spelzer, I. 2015. Determinants of Sexual Activity and Pregnancy among Unmarried Young Women in Urban Kenya: A Cross-Sectional Study. Plos One. doi:10.1371/journal.pone.0129286

[19] Saleeby, E., O’Donnell, B., Jackson, A., Muniz, C., Chung, P., Sufrin, C. 2019. Tough Choices: Exploring Decision-Making for Pregnancy Intentions and Prevention Among Girls in the Justice System. Journal of Correctional Health Care. doi: 10.1177/1078345819880307

[20]Smith, J., Skinner, S., Fenwick, J. 2013. Preconception reflections, postconception intentions: the before and after of birth control in Australian adolescent females. Sexual Health. doi:10.1071/SH13020

[21] Sychareun, V., Vongxay, V., Houaboun, S., Thammavongsa, V., Phummavongsa, P., Chaleunvong, K., Durham, J. 2018. Determinants of adolescent pregnancy and access to reproductive and sex health services for married and unmarried adolescents in rural Lao PDR: a qualitative study. BMC Pregnancy and Childbirth. doi : 10.1186/s12884-018-1859-1

[22] Umaroh, A., Kusumawati, Y., Kasjono, H. 2015. 
Hubungan antara Faktor Internal dan Faktor Eksternal dengan Perilaku Seks Pranikah Remaja di Indonesia. Jurnal Kesehatan Masyarakat Andalas. p-ISSN 1978-3833

\section{PROFIL PENULIS UTAMA}

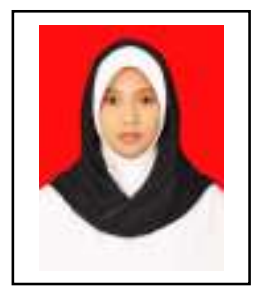

Nama : Nur Fitri Ayu Pertiwi

TTL : : Surakarta, 27 Februari 1996

No. HP : 087738643605

Alamat : Polengan RT 01 RW 01, Polengan, Kec. Srumbung, Kab. Magelang, Prov. Jawa Tengah

Riwayat Pendidikan :

Sekolah Dasar Negeri 2 Muntilan, Kabupaten Magelang, Jawa Tengah (2002-2008)

Sekolah Menengah Pertama 1 Muntilan, Kabupaten Magelang, Jawa Tengah (2008-2010)

Sekolah Menengah Atas 1 Sleman, Kabupaten Sleman, Daerah Istimewa Yogyakarta (2010-2013)

Diploma III Kebidanan Fakultas Kedokteran Universitas Sebelas Maret Surakarta (2013-2016)

Diploma IV Bidan Pendidik Fakultas Kedokteran Universitas Sebelas Maret Surakarta (2016-2017)

Magister Kebidanan Universitas 'Aisyiyah Yogyakarta (2018-sekarang)

Penelitian :

Asuhan Kebidanan Gangguan Reproduksi pada Ny. T $\mathrm{P}_{4} \mathrm{~A}_{0}$ dengan Perdarahan Uterus Disfungsional di RSUD Surakarta Tahun 2016

Hubungan Pengetahuan Kesehatan Reproduksi dengan Perilaku Seks Pranikah di SMP Negeri 2 Srumbung Kabupaten Magelang Tahun 2017

Systematic Literature Review : Penyebab dan Dampak Kehamilan Tidak Diinginkan pada Remaja Tahun 2018 